J. Clin. Chem. Clin. Biochem.

Vol. 16, 1978, pp. 213-221

\title{
An Evaluation of the Jeol Clinalyzer
}

\author{
By I. R. Hainsworth, E. Jean McAllister, E. Simpson, A. Duncan and L. B. Roberts \\ Department of Biochemistry, Gartnavel General Hospital, Glasgow G12 OYN, United Kingdom
}

(Received July, 19/October 31, 1977)

Summary: The Jeol Clinalyzer was evaluated over a period of 15 weeks. The operating principles are briefly described. The functions of the mechanical components were tested and assessments made of the instrument's safety and reliability. The mechanical and electrical reliability of the instrument was excellent and the pumps and spectrophotometer gave good accuracy and precision.

Between-batch precision of the analytical methods was good for urea, protein and bilirubin and acceptable for alkaline phosphatase and aspartate transaminase. There was a poor relative accuracy for alkaline phosphatase and aspartate transaminase and some proportional inaccuracy for urea and bilirubin.

\section{Evaluation des Joel Clinalyzer}

Zusammenfassung: Der Joel Clinalyzer wurde über einen Zeitraum von 15 Wochen einer Bewertung unterzogen. Die Funktionsprinzipien werden kurz beschrieben. Die Funktion der Mechanik wurde geprüft; die Sicherheit und Zuverlässigkeit des Instruments wird beurteilt. Die mechanische und elektrische Zuverlässigkeit des Geräts war ausgezeichnet und Pumpen und Spektrophotometer zeigten eine gute Richtigkeit und Genauigkeit. Die Präzision von Serie zu Serie für analytische Methoden war gut für Harnstoff, Protein und Bilirubin und annehmbar für alkalische Phosphatase und Aspartattransaminase. Die Prüfung ergab eine schwache relative Richtigkeit für alkalische Phosphatase und Aspartattransaminase sowie gewisse proportionale Fehler für Harnstoff und Bilirubin.

\section{Description of the Machine}

The Jeol N6 Clinalyzer is a six channel discrete analyzer which can measure enzyme catalytic activity or substrate concentration by reaction rate as well as carrying out colorimetric end-point assays. It is of Japanese manufacture and the U.K. agents are Vickers Medical, Basingstoke. It is at present the only instrument available which can measure up to 6 enzymes in the one sample, simultaneously, by reaction rate methods.

The instrument is illustrated in figure 1.

Samples are aspirated from plastic cups on a turntable sampler and are drawn into the sampling valve. The sampling valve is diagramatically illustrated in figure 2 . It consists of a PTFE rotor between two stators. The rotor has holes in it which, during introduction of the sample, align with passages in the stators and the sample is drawn into the holes in the rotor by the action of the sampling pump. The rotor then turns through an angle of about $20^{\circ}$ and the holes which now contain the samples for the individual channels are lined up with a second set of passages in the stators which connect with the reagent pump and with the reaction vessels. The samples are then washed into the reaction vessels with reagent.

There are two reagent pumps each capable of handling 6 reagents. They are piston operated. Pump 1 supplies one reagent, or serum diluent, per analytical channel. Pump 2 is used to supply further reagents to any channel. The maximum number of reagents which can be used is therefore 12 . Reagent volumes are fixed at $0.5,1.0$ or $2.0 \mathrm{ml}$ and each test is carried out in a final volume of between 2.0 and $3.0 \mathrm{ml}$.

The chemical reactions and the measurements of absorbance take place in cylindrical glass cuvettes, $12.4 \mathrm{~mm}$ in diameter. Twelve cuvettes are mounted on a carouselle which rotates through $1 / 12$ revolution each minute (reaction/detection assembly). There are 6 reaction/detection assemblies in the instrument, one for each analytical channel. Figure 3 shows vertical and horizontal sections through an assembly. The light 


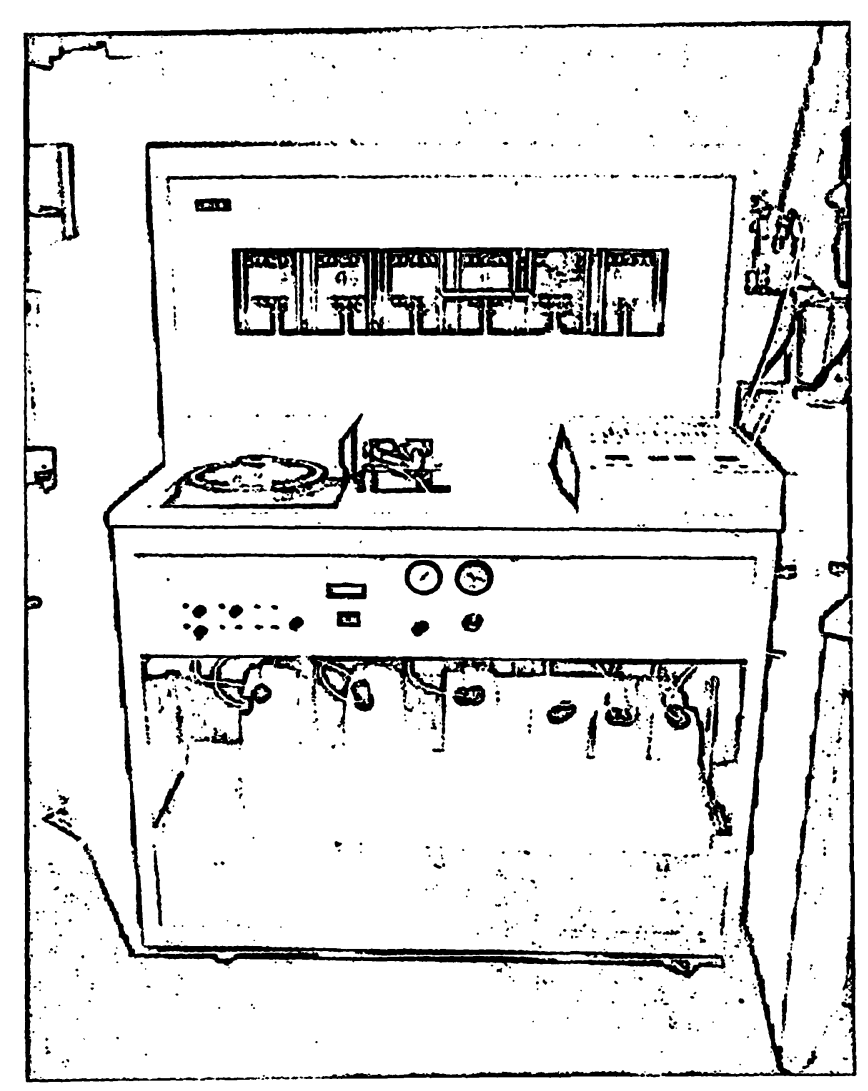

Fig. 1. The Jeol N6 Clinalyzer
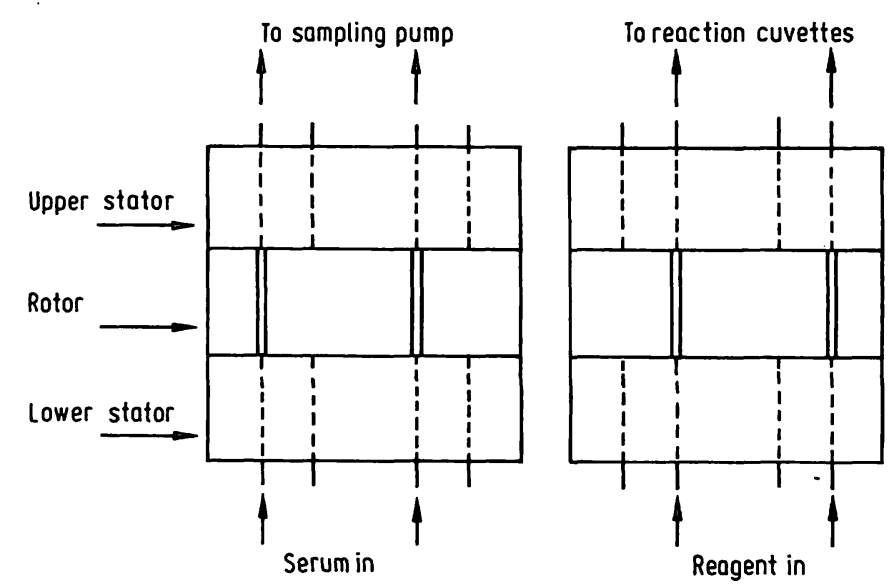

Fig. 2. The sampling valve in schematic section

source is a tungsten lamp which is mounted above the carouselle and the light path is directed down the axis of rotation of the assembly. A $45^{\circ}$ mirror directs the light beam through the cuvettes. In the case of end-point channels the mirror splits the light between the cuvette and a reference photodetector. In the case of reactionrate channels the mirror is $100 \%$ reflecting and there is no reference detector. Wavelength selection is by an interference filter placed between the cuvette and the photodetector. Cut-off filters may also be fitted between the lamp and the cuvette and between the cuvette and the photodetector.

The cuvette in position 1 (see fig. 3 ) receives the sample and reagent 1 . As the cuvette rotates through positions 2-9 further reagents may be added. After reagent additions the mixture is stirred by passing air bubbles through it for 6 seconds. In position 10 the cuvette comes into the light path. In positions 11 and 12 the cuvette is washed and air dried. The time lapse between adding a starting reagent for a reaction rate method and beginning to monitor the absorbance change is 24 seconds. However, the starting reagent probably remains layered under the first reagent and the reaction does not start until the cuvette contents are mixed. The time lapse between mixing and beginning to monitor the absorbance change is 15 seconds. The absorbance is then monitored for 44 seconds.

The reaction/detection assemblies and the sampling valve are contained in an air-bath at $37^{\circ} \mathrm{C}$. Reagents pass through a pre-heat water bath also at $37^{\circ} \mathrm{C}$ before entering the air bath.

A hard wired data processor checks reaction rate analyses for linearity and calculates the results.

The rate of analysis is 60 samples/hour and the minimum sample volume is about $0.4 \mathrm{ml}$. Up to $60 \times 6$ (channels) $=360$ tests per hour are available and all tests are carried out on all samples. Sample identification is by tray and cup number.

The instrument is calibrated by carrying out an 18 sample calibration run (usually once a day) during which, for each reaction-rate channel, the operator enters a factor relating $\Delta \mathrm{A} / \mathrm{min}$ to enzyme activity and, for each endpoint channel, the standard concentration. The first part of the calibration run consists of 12 water samples. The instrument determines the reagent blank value for each reaction cuvette in the end-point channels and stores these values. For reaction-rate channels, the blank $(\Delta \mathrm{A} /$ min in the absence of sample) is determined once. One standard is then presented for each end-point channel. The same reference serum may be used for all channels, or alternatively, each channel can have its own primary standard.

Fourteen reaction-rate and thirteen end-point methods are available.

The installation requirements for the instrument are shown in table 1.

Transmitting the data to a computer for report production could be done off-line or on-line. Adding a paper tape punch to the printer would allow batch transmission of data on paper tape. The Clinalyzer has the facility for direct interfacing to a computer. The data processor unit is then dispensed with and the operations which it performs carried out by the computer. 

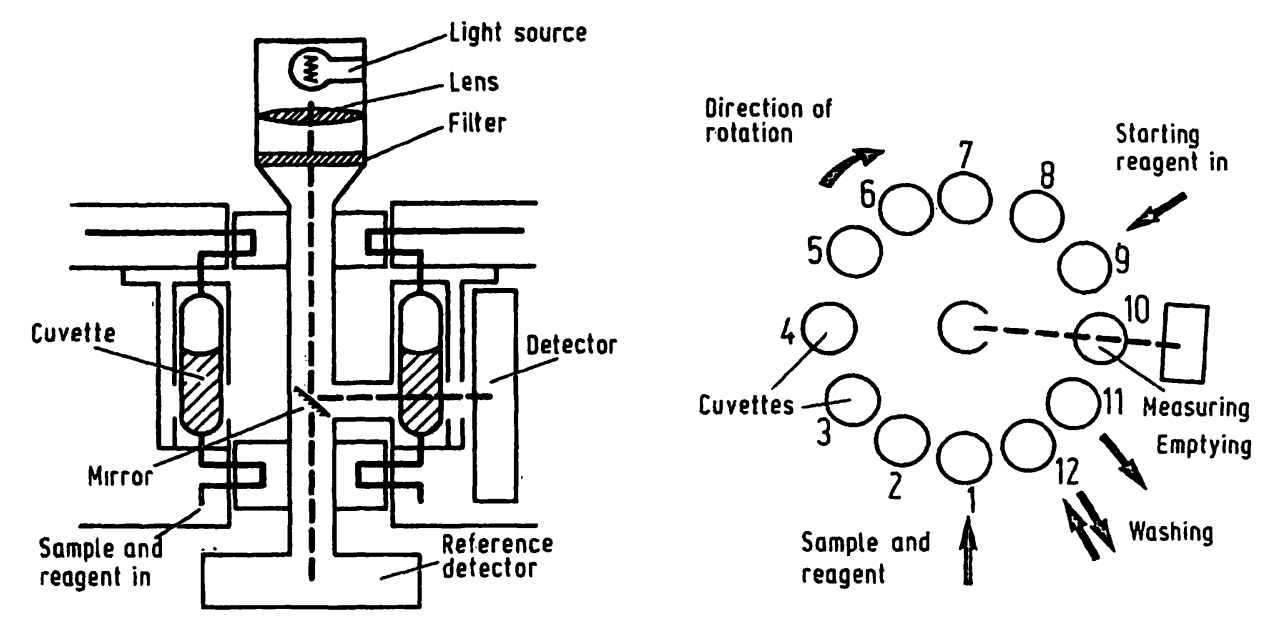

Fig. 3. A reaction/detection assembly in schematic sections

Tab. 1. Installation Requirements

\section{Clinalyzer (N6)}

Dimensions: Power supply: Power consumption:

Service Requirements:

$100 \mathrm{~cm}$ wide $\times 81 \mathrm{~cm}$ deep $\times 141 \mathrm{~cm}$ high. 100 V 50/60 Hz. single phase.

1.7 kVA Maximum.

Tap water.

Deionised water $-151 / \mathrm{h}$.

Vacuum - A vacuum pump is supplied. Compressed air.

Waste - a floor level drain is needed.

Environment:

Temperature should be maintained in the range $20-25^{\circ} \mathrm{C}$.

Data Processor

Dimensions:

Power supply:
$70 \mathrm{~cm}$ wide $\times 65 \mathrm{~cm}$ deep $\times 95 \mathrm{~cm}$ high. No separate supply is required.

\section{Electrical and Mechanical Evaluation}

\section{Electrical Safety}

The instrument was examined for electrical safety by staff of the Common Services Agency (Scottish Home and Health Department). As well as referring to some minor problems which were rectified on site by Vickers, the electrical safety report makes the following points:

a. The earth continuity resistance was found to be satisfactory.

b. The earth leakage current was $100 \mu \mathrm{A}$ with the mains supply leads connected normally and $110 \mu \mathrm{A}$ with these leads reversed.

c. The secondary (module) fuses are wired so that the live terminal is nearest to the panel. The live termination should be furthest from the equipment panel.

d. The plug on the mains supply inlet could be better secured as the securing mechanism tends to pull the plug sideways.

\section{Reliability}

The evaluation was carried out over a 15 week period during which the instrument was run for about 500 . hours - and was on standby when not in operation.

\section{Reagent Volumes}

With the reagent pumps delivering water, 20 samples from each pump channel were collected and weighed. Results are shown in table 2 . The accuracy and precision of the pumps is considered satisfactory.

Tab. 2. Reagent Volumes

\begin{tabular}{lllll}
\hline & & $\begin{array}{l}\text { Nominal } \\
\text { Volume (ml) }\end{array}$ & $\begin{array}{l}\text { Mean } \\
\text { Measured } \\
\text { Volume (ml) }\end{array}$ & $\begin{array}{l}\text { C.V. } \\
(\%)\end{array}$ \\
\hline Pump 1 & Channel 1 & 2 & 1.9645 & 0.018 \\
Pump 1 & Channel 2 & 2 & 1.9619 & 0.037 \\
Pump 1 & Channel 3 & 2 & 1.9680 & 0.055 \\
Pump 1 & Channel 4 & 2 & 1.9684 & 0.013 \\
Pump 1 & Channel 5 & 2 & 1.9708 & 0.056 \\
Pump 1 & Channel 6 & 2 & 1.9655 & 0.043 \\
Pump 2 & Channel 1 & 0.5 & 0.4917 & 0.11 \\
Pump 2 & Channel 2 & 0.5 & 0.4904 & 0.12 \\
Pump 2 & Channel 3 & 0.5 & 0.4907 & 0.10 \\
Pump 2 & Channel 4 & 0.5 & 0.4842 & 0.11 \\
Pump 2 & Channel 5 & 0.5 & 0.4884 & 0.082 \\
Pump 2 & Channel 6 & 1 & 1.0041 & 0.071 \\
\hline n=20 & & \multicolumn{3}{c}{}
\end{tabular}




\section{Sample Volumes}

A solution of $\mathrm{Na}^{125} \mathrm{I}$ in serum was sampled 20 times and the individual samples for each analytical channel were collected and counted to a total of 100000 counts. An accurately known volume of serum was also counted, as a standard. Results are shown in table 3. The C.V.'s are corrected for the error attributable to counting.

The precision of sampling is conșidered satisfactory but the volumes of the samples are substantially less than the nominal capacities of the sampling valve.

We considered it possible that the sample was being diluted with water before reaching the sampling valve. Between samples, the sample pump back-washes the sampling valve and the tubing which connects the sampling valve and the pipette with de-ionised water, and leaves the tubing full of water. Air, serum, air and tap-water are then introduced in that order, and as the serum is drawn towards the sampling valve, it could become diluted by some of the water which precedes it. We carried out an experiment to check for this effect.

\section{Check for Sample Dilution}

A solution of $\mathrm{K}^{125} \mathrm{I}(18.5 \mathrm{MBq} / \mathrm{l})$ in aqueous potassium iodide $(1 \mathrm{~g} / \mathrm{l})$ was supplied to the sampling pump in place of the de-ionised water which is normally used for back-washing the sampling system. We then sampled serum 10 times and collected the samples for the individual channels. These samples were then counted and the volume of the labelled potassium iodide solution which each contained was calculated. Results are shown in table 4. The channels are listed in the order in which

Tab. 3. Sample Volumes.

\begin{tabular}{llll}
\hline Channel & $\begin{array}{l}\text { Nominal } \\
\text { Volume }(\mu \mathrm{l})\end{array}$ & $\begin{array}{l}\text { Mean } \\
\text { Volume }(\mu \mathrm{l})\end{array}$ & $\begin{array}{l}\text { C.V. } \\
(\%)\end{array}$ \\
\hline 1. (Aspartate & & & \\
$\quad$ transaminase) & 50 & 46.61 & 0.27 \\
2. (Alkaline Phosphatase) & 10 & 9.46 & 0.53 \\
3. (Urea) & 10 & 9.09 & 0.43 \\
4. (Protcin) & 20 & 17.98 & 0.38 \\
5. (Bilirubin) & 20 & 17.45 & 0.51 \\
6. (Bilirubin Blank) & 20 & 16.32 & 0.53 \\
\hline $\mathrm{n}=20$ & & &
\end{tabular}

Tab. 4. Water Contents of the Samples.

\begin{tabular}{lllll}
\hline $\begin{array}{l}\text { Channel } \\
\text { No }\end{array}$ & $\begin{array}{l}\text { Nominal } \\
\text { Sample } \\
\text { Volume } \\
(\mu l)\end{array}$ & $\begin{array}{l}\text { Mean } \\
\text { Volume of } \\
\text { water } \\
\text { included in } \\
\text { sample }(\mu l)\end{array}$ & $\begin{array}{l}\text { Volume of } \\
\text { Water as \% } \\
\text { of nominal } \\
\text { volume }\end{array}$ & $\begin{array}{l}\text { Total } \\
\text { Volume of } \\
\text { sample } \\
(\text { serum }+ \\
\text { water })(\mu l)\end{array}$ \\
\hline 6 & 20 & 4.68 & 23.4 & 21.00 \\
5 & 20 & 3.27 & 16.3 & 20.72 \\
3 & 10 & 1.33 & 13.3 & 10.42 \\
4 & 20 & 2.30 & 11.5 & 20.28 \\
2 & 10 & 0.98 & 9.8 & 10.44 \\
1 & 50 & 4.33 & 8.7 & 50.94 \\
\hline
\end{tabular}

the sample ports are filled in the sampling valve. The sample for channel 6 is taken from the front of the column of serum.

The column of serum becomes mixed with water before it reaches the sampling valve and this dilution is progressive from the rear to the front of the column. This effect accounts for the delivery of samples containing an amount of serum which is less than the nominal volume of the sampling valve. When the serum and water components of each sample are summed (table 4, column 5) the total is always within $1 \mu$ of the nominal volume of the sampling valve.

It becomes evident that the precision of sampling depends upon the precision with which the column of serum is positioned relative to the sampling valve, which in turn depends upon the reproducible operation of the sampling pump. As has been shown, the precision of sampling is sâtisfactory but a slight deterioration in the action of the sampling pump could significantly affect the accuracy of the analysis.

\section{Photometers}

The optical filter combinations used for wavelength selection were scanned on a recording spectrophotometer. They were found to transmit maximally at $6 \mathrm{~nm}$, or less, from the stated values and the bandwidths at half-maximum transmittance were between 14 and $19 \mathrm{~nm}$.

Photometric accuracy was determined by comparing the absorbance, at several concentrations, of solutions of $\mathrm{NADH}, p$-nitrophenol and toluidine blue on the Clinalyzer and on a Pye-Unicam SP 1800 spectrophotometer. After applying a correction for the different path lengths in the two instruments, the Clinalyzer was found to read 0.13 absorbance units lower then the SP 1800 at an absorbance of 1.0 and a wavelength of $340 \mathrm{~nm}$, 0.05 absorbance units lower than the SP 1800 at an absorbance of 1.0 and a wavelength of $410 \mathrm{~nm}$ and 0.04 absorbance units lower than the SP 1800 at an absorbance of 1.0 and a wavelength of $600 \mathrm{~nm}$.

The underestimation of absorbance probably results from the use of relatively wide bandwidth filters, and to compensate for this underestimation the manufacturer provides values for the molar absorptivities (litre $\left.\mathrm{mol}^{-1} \mathrm{~cm}^{-1}\right)$ of NADH $\left(5.4 \times 10^{3}\right)$ and $p$-nitrophenol $\left(17.8 \times 10^{3}\right)$, derived from measurements made on the Clinalyzer, and suggests that these values be used in calculating enzyme activities. We used these estimates of the molar absorptivities during the clinical laboratory evaluation.

There was a linear relationship between absorbance and concentration up to an absorbance of 1.2 , at the 3 wavelengths tested, with negative departures from linearity thereafter. The end-point channels always operate at 
absorbances of less than 1.2 but the absorbance of some samples may exceed 1.2 in reaction rate channels.

The precision of one of the photometers $(600 \mathrm{~nm})$ was checked by taking readings at 1 -minute intervals for 6 hours. With water in the cuvettes the mean absorbance was $0.000028 \pm 0.00013$ absorbance units (2SD). With a solution of toluidine blue of absorbance 0.06 , the C.V. of replicate absorbance readings was $0.16 \%$, and at an absorbance of 0.62 the C.V. was $0.14 \%$. $n=360$ in all cases. Photometric precision and photometer longterm stability is considered good.

\section{Temperature Control}

A precision mercury in glass thermometer with a scale length of $50 \mathrm{~mm} /{ }^{\circ} \mathrm{C}$ and certified accuracy of $\pm 0.02^{\circ} \mathrm{C}$ was placed inside the air-bath where it could be seen through the transparent front cover. Readings were taken at 30-minute intervals during a 6 hour run. The temperature stability of the air-bath was checked using a thermistor probe linked to a recorder. The full scale on the recorder corresponded to $2^{\circ} \mathrm{C}$. A continuous recording was made during the same 6 hour run. The accuracy of the air-bath temperature is specified by the manufacturer as $37^{\circ} \mathrm{C} \pm 0.1^{\circ} \mathrm{C}$ and the maximum temperature variation is specified as $0.03^{\circ} \mathrm{C}$. We consider these specifications to be met.

\section{Carryover}

The method of Broughton et al. (1) was used to measure carryover. Readings were made on 3 successive aliquots (al, a2, a3) of a serum with high levels of the substances being measured followed by readings on 3 succêssive aliquots (b1, b2, b3) of a serum with low levels. Carryover was calculated from:

$$
K=\frac{b 1-b 3}{a 3-b 3}
$$

Tab. 5. Methods and Reagents.
Ten measurements of $\mathrm{K}$ were made. The mean value for $\mathrm{K}$ was statistically not significantly different from zero, in all channels.

\section{Clinical Laboratory Evaluation}

The analytical channels which were available on the particular instrument under evaluation and the methods used are shown in table 5 . Channel 6 is a bilirubin blank. Urea, protein and bilirubin channels were calibrated using Autoset $\mathrm{H}$ (Wellcome Reagents Ltd, Beckenham, U.K.). Factors relating $\Delta \mathrm{A} / \mathrm{min}$ to enzyme activity for aspartate transaminase and alkaline phosphatase were calculated from our own estimates of reagent and sample volumes and the values for the molar absorptivity of NADH and $p$-nitrophenol supplied by Vickers Medical.

\section{Precision}

Within-run and between-run precision was determined according to the protocol proposed by the (USA) National Committee for Clinical Laboratory Standards the NCCLS protocol (2).

Quality Assurance Serum (General Diagnostics, Morris Plains, N. J., USA) was reconstituted to give 3 different concentration levels for each constituent ("low", "mid", "high"). A total of 40 precision runs, each of 45 minutes duration was carried out. Each run was made up of the 9 sample sets shown in table 6 . These samples sets were arranged in a random fashion in accordance with the NCCLS protocol so that the sampling order was different for each run.

Estimates of the standard deviation of replicate analyses (S.D.) were calculated according to formula:

$$
\text { S.D. }=\sqrt{\frac{\Sigma(\mathrm{x}-\overline{\mathrm{x}})^{2}}{\text { degrees of freedom }}}
$$

\begin{tabular}{|c|c|c|}
\hline Analysis & Methọd & Reagent Sources \\
\hline Aspartate transaminase & $\begin{array}{l}\text { Kinetic. } L \text {-aspartate, } 2 \text {-oxoglutarate. Oxaloacetate reacts with NADH } \\
\text { in a indicator reaction catalysed by malate dehydrogenase }\end{array}$ & $\begin{array}{l}\text { NADH - Sigma } \\
\text { Malate dehydrogenase - Whatman } \\
\text { Lactate dehydrogenase - Boehringer } \\
\text { Others - BDH }\end{array}$ \\
\hline Alkaline Phosphatase & Kinetic. $\ddot{p}$-nitrophènyl phosphate. Diethanolamine buffer pH 9.8 . & All rcagents - BDH \\
\hline Urea & $\begin{array}{l}\text { Kinetic. Urease. Ammonia reacts with 2-oxoglutarate and NADH in } \\
\text { an indicator reaction catalysed by glutamate dehydrogenase }\end{array}$ & $\begin{array}{l}\text { Urease, ADP, NADH and glutamatc } \\
\text { dehydrogenase from Sigma. } \\
\text { Others - BDH }\end{array}$ \\
\hline Total Protein & End Point. Biuret, & All reagents - BDH \\
\hline Bilirubin & End-point. Jendressik \& Cleghorn. & All reagents - BDH \\
\hline
\end{tabular}

Sigma = Sigma Chemical Co. Ltd., London, U.K.

Whatman = Whatman Bioçhemicals Ltd., Maidstone, Kent, U.K.

Boehringer $=$ Boehringer Corporation Ltd., London, U.K.

BDH = BDH Chemicals Ltd., Poole, Dorset., U.K. 
Tab. 6. Composition of the Sample Sets for Assessment of Precision.

\begin{tabular}{lllll}
\hline Set Number & \multicolumn{4}{l}{ Order of Samples in each set. } \\
& A & B & C & D \\
\hline 1 & H & H & H & H \\
2 & M & H & H & H \\
3 & L & H & H & H \\
4 & H & M & M & M \\
5 & M & M & M & M \\
6 & L & M & M & M \\
7 & H & L & L & L \\
8 & M & L & L & L \\
9 & L & L & L & L \\
\hline
\end{tabular}

$H$ represents a sample of high concentration $M$ represents a sample of mid concentration $L$ represents a sample of low concentration

For within-run precision including the effects of carryover, $x$ represents an individual value for the high serum in position $B$ in the sample sets. $\bar{x}$ represents the mean of the 9 values obtained for the high serum in positions $B$, $C$ and $D$ in that run. The number of degrees of freedom is twice the number of runs. Estimates for the mid and low sera were made analogously.

Within-run precision excluding the effect of carryover was calculated for each concentration using the same equation $-\mathrm{x}$ now represents an individual value for serum in position $C$ or $D . \bar{x}$ takes the same values as before. The number of degrees of freedom is 5 times the number of runs.

The total between-run precision was calculated in the same manner. $x$ represents the individual values for the high serum in position $B$ in the sample sets and $\bar{x}$ represents the overall (between run) mean of the values obtained for the high serum in position $B$ in the sample sets in all 40 runs. The number of degrees of freedom is one less than the total number of observations. Estimates for the mid and low sera were made analogously.

Too many of the low (43\%) and mid (30\%) aspartate transaminase assays were indicated by the Clinalyzer as having a non-linear reaction course to allow the calculations of within-batch precision according to the NCCLS method. Figures for between-batch precision were calculated from linear assays only. Results are shown in table 7.

Because the NCCLS protocol uses short runs (45-minute duration on the Clinalyzer), we made an additional assessment of within-run precision and of drift in a run of 5 hours duration. For alkaline phosphatase, urea; protein and bilirubin the drift was small and within-run precision close to the values estimated according to the NCCLS protocol. Within-batch precision in the aspartate transaminase channel was $6.8 \%$ (C.V.) at a mean value of $75 \mathrm{U} / 1$ which compares with a within-run C.V. of $1.8 \%$ at a mean level of $92 \mathrm{U} / 1$ estimated according to the NCCLS protocol. There was a steady upward drift in
Tab. 7. Precision.

\begin{tabular}{|c|c|c|c|c|}
\hline Analysis & $\begin{array}{l}\text { Mean } \\
\text { (catalytic) } \\
\text { concen: } \\
\text { tration }\end{array}$ & $\begin{array}{l}\text { C.V. [\%] } \\
\text { within run } \\
\text { excluding } \\
\text { carryover }\end{array}$ & $\begin{array}{l}\text { C.V. }[\%] \\
\text { within run } \\
\text { including } \\
\text { carryover }\end{array}$ & $\begin{array}{l}\text { C.V. }[\%] \\
\text { between } \\
\text { run }\end{array}$ \\
\hline $\begin{array}{l}\text { Aspartate } \\
\text { transaminase } \\
{[\mathrm{U} / 1]}\end{array}$ & $\begin{array}{l}16.2 \\
28.7 \\
92.4\end{array}$ & $\overline{-}$ & $\begin{array}{l}- \\
\overline{1.8}\end{array}$ & $\begin{array}{l}8.7 \\
7.5 \\
3.8\end{array}$ \\
\hline $\begin{array}{l}\text { Alkaline } \\
\text { Phosphatase } \\
{[\mathrm{U} / 1]}\end{array}$ & $\begin{array}{r}53 \\
99 \\
560\end{array}$ & $\begin{array}{l}3.1 \\
1.4 \\
0.6\end{array}$ & $\begin{array}{l}1.5 \\
1.8 \\
0.7\end{array}$ & $\begin{array}{l}5.3 \\
9.7 \\
8.0\end{array}$ \\
\hline $\begin{array}{l}\text { Urea } \\
\text { [mmol/l] }\end{array}$ & $\begin{array}{r}4.84 \\
8.80 \\
21.52\end{array}$ & $\begin{array}{l}1.2 \\
1.0 \\
0.9\end{array}$ & $\begin{array}{l}1.2 \\
1.2 \\
0.9\end{array}$ & $\begin{array}{l}2.1 \\
1.5 \\
1.4\end{array}$ \\
\hline $\begin{array}{l}\text { Protein } \\
{[\mathrm{g} / \mathrm{l}]}\end{array}$ & $\begin{array}{r}26.8 \\
49.1 \\
105.9\end{array}$ & $\begin{array}{l}0.7 \\
0.6 \\
0.5\end{array}$ & $\begin{array}{l}0.6 \\
0.6 \\
0.5\end{array}$ & $\begin{array}{l}1.0 \\
0.9 \\
1.4\end{array}$ \\
\hline $\begin{array}{l}\text { Bilirubin } \\
{[\mu \mathrm{mol} / 1]}\end{array}$ & $\begin{array}{r}18.4 \\
34.7 \\
150.6\end{array}$ & $\begin{array}{l}2.9 \\
2.4 \\
0.6\end{array}$ & $\begin{array}{l}3.5 \\
2.2 \\
0.7\end{array}$ & $\begin{array}{l}4.9 \\
4.2 \\
1.8\end{array}$ \\
\hline
\end{tabular}

aspartate transaminase results during the 5 hour run, starting at $69 \mathrm{U} / 1$ and reaching $82 \mathrm{U} / 1$ after 5 hours.

Precision was outstandingly good for urea, protein and bilirubin and was acceptable for alkaline phosphatase and aspartate transaminase. The aspartate transaminase channel was susceptible to drift, and also produced a high incidence of non-linear reactions. However, nonlinear reactions were associated with "normal" aspartate transaminase levels and the S. D. of non-linear assays was not significantly different from the S.D. of linear assays. It is therefore likely that the criteria imposed for linearity (less than $12 \%$ difference in slope between two successive 22 second portions of the curve) may be too stringent for this assay. Less than $0.5 \%$ of alkaline phosphatase results were non-linear and a non-linear urea result was a rarity.

Estimates of precision including and excluding the effects of carryover were close to each other, and this is in keeping with our finding that carryover was undetectable.

\section{Linearity}

The linear range of each channel was investigated separately by preparing a series of mixtures of 2 sera containing, respectively, high and low concentrations of the constituent being measured. The results are shown in table 8.

Tab. 8. Linear Range of Clinalyzer Methods.

\begin{tabular}{ll}
\hline Analysis & Linear Range \\
\hline Aspartate tramsaminase & $0-1700 \mathrm{U} / 1$ \\
Alkaline Phosphatase & $0-3500 \mathrm{U} / 1$ \\
Urea & $0-90 \mathrm{mmol} / 1$ \\
Protein & $0-130 \mathrm{~g} / \mathrm{l}$ \\
Bilirubin & $0-350 \mu \mathrm{mol} / 1$ \\
\hline
\end{tabular}




\section{Accuracy}

125 serum samples (portions of patient specimens received in the laboratory) were collected. Urea, total protein and bilirubin were measured by selected methods on the day the samples were collected. The balance of the material was deep-frozen. On each of 5 days we took 25 samples, analysed them on the Clinalyzer and measured aspartate transaminase and alkaline phosphatase by our selected methods.

The methods which were selected for comparison with the Clinalyzer were as follows:

Total Protein and Bilirubin - SMA 12/60 (Technicon Instruments Co. Ltd., Basingstoke, UK). Methods chemically similar to those on the Clinalyzer. Autoset $\mathrm{H}$ as a standard.

Urea - SMA 6/60. Diacetyl monoxime method. Autoset $\mathrm{H}$ as standard.

\section{Aspartate transaminase - Vitatron AKES. (Fisons} Scientific Apparatus Ltd. Loughborough, UK). Optimised reaction rate method using reagents from Boehringer Corporation Ltd., London UK.

Alkaline Phosphatase - Vitatron AKES. p-nitrophenyl phosphate as substrate. Optimised reaction rate method using Boehringer reagents.

22 non-linear aspartate transaminase assays from the Clinalyzer were rejected. There were no non-linear alkaline phosphatase or urea assays. Results are shown in table 9.

Aspartate transaminase - There is a good correlation but with more marked scatter at the lower levels. The small intercept represents the blank for the AKES which was not subtracted. Across the whole range of values, the Clinalyzer results are, on an average, $22 \%$ lower than the AKES results. Reaction conditions for aspartate transaminase on both instruments are similar (tab. 10), so an experiment was carried out to determine whether the difference in results was due to a difference in the quality of reagents used with the two instruments.

The diluent and starter reagents used with the AKES (Boehringer) were reconstituted with distilled water for use with the Clinalyzer so that the final substrate and coenzyme concentrations in the cuvette were the same

Tab. 9. Correlation of Results: Clinalyzer V Selected' Methods.

\begin{tabular}{|c|c|c|c|c|}
\hline Analysis and units & $\begin{array}{l}\text { Range of } \\
\text { Values }\end{array}$ & M & $\mathrm{C}$ & $\mathbf{r}$ \\
\hline $\begin{array}{l}\text { Aspartate transaminase }[U / 1] \\
\text { Alkaline Phosphatase }[U / 1]\end{array}$ & $\begin{array}{r}14-2615 \\
1.00-3500\end{array}$ & $\begin{array}{l}0.78 \\
0.69\end{array}$ & $\begin{array}{l}-5.9 \\
+4.5\end{array}$ & $\begin{array}{l}0.999 \\
0.999\end{array}$ \\
\hline Ưrea [mmol/1] & $1.2-48.9$ & 0.86 & +0.39 & 0.997 \\
\hline Protein [g/1] & $50-84$ & 1.04 & $=3.7$ & $0: 962$ \\
\hline Bilirubin [ $\mu \mathrm{mol} / 1]$ & $5-25$ & 0.77 & -0.02 & 20.934 \\
\hline Bilirubin [umol/1] & $5-460$ & 0.95 & -2.2 & $0: 999$ \\
\hline
\end{tabular}

Clinalyzer $=\mathbf{M} \times($ Selected Method $)+C$

$r$ is the correlation coefficient.
Tab. 10. Comparison of Reaction Conditions for Aspartate transaminase.

\begin{tabular}{lcc}
\hline & Clinalyzer & AKES \\
\hline Phosphate buffer pH 7.4 [mmol/1] & 98 & 80 \\
L-Aspartate [mmol/1] & 156 & 200 \\
2-oxoglutarate [mmol/1] & 12 & 12 \\
NADH [mmol/1] & 0.18 & 0.18 \\
Lactate dehydrogenase [U/1] & 600 & $>1200$ \\
Malate dehydrogenase [U/1] & 1000 & $>600$ \\
Volume fraction of sample & 0.02 & 0.161 \\
Temperature [ ${ }^{\circ} \mathrm{C}$ ] & 37 & 37 \\
\hline
\end{tabular}

on both instruments. The only difference remaining between the two methods was that, with the Clinalyzer, it is impossible to use more than $50 \mu$ of serum in a final volume of $2500 \mu \mathrm{l}$ whereas with the AKES $100 \mu \mathrm{l}$ of serum are used in a final volume of $620 \mu \mathrm{l}$. In a comparison using 56 patient sera, the Clinalyzer gave lower results than the AKES,

$$
\text { Clinalyzer }=0.87 \times(\text { AKES })-5.3, r=0.999, \mathrm{n}=56
$$

although the results from the two instruments were in closer agreement than before.

To investigate the effect of the different volume fractions, patient samples and quality control materials were assayed with the AKES using Boehringer reagents and (1) using $100 \mu \mathrm{l}$ serum (volume fraction of sample: 0.161 ) (2) using $15 \mu \mathrm{l}$ serum (volume fraction of sample : 0.028 ), i.e. a similar volume fraction of sample to that used on the Clinalyzer. This experiment was performed on the AKES as it is difficult to change sample volumes on the Clinalyzer. Reagent blanks were subtracted. The following regression line was obtained:

$\operatorname{AKES}(15 \mu \mathrm{l})=1.02 \times \operatorname{AKES}(100 \mu \mathrm{l})-1.4, \mathrm{r}=0.999$, $\mathrm{n}=34$.

The difference in the results from the two instruments is not therefore accounted for by the different volume fractions of serum which they use.

Alkaline phosphatase - There is a very good correlation between the two methods but, across the whole range, Clinalyzer results are lower than those from the AKES - more than $30 \%$ lower on an average. Experiments were carried out, as for aspartate transaminase, to determine the effects of reagent quality and sample volume fraction. Table 11 compares reaction conditions in the Clinalyzer and the AKES for alkaline phosphatase.

Tab. 11. Comparison of Reaction Conditions for Alkaline Phosphatase.

\begin{tabular}{lcc}
\hline & Clinalyzer & AKES \\
\hline Wavelength [nm] & 410 & 405 \\
Diethanolamine [mol/1] & 1.0 & 1.0 \\
p-nitrophenyl phosphate [mmol/1] & 14 & 10 \\
Magnesium [mmol/1] & 0 & 0.5 \\
pH & 9.80 & 9.80 \\
Temperature $\left[{ }^{\circ} \mathrm{C}\right]$ & 37 & 37 \\
Volume fraction of sample & 0.004 & 0.018 \\
\hline
\end{tabular}


Buffer for the Clinalyzer ( $1 \mathrm{~mol} / \mathrm{l}$ diethanolamine) was obtained by diluting the diethanolamine buffer from the Boehringer Kit. Starter reagent was made using Boehringer $p$-nitrophenyl phosphate dissolved in buffer. Under these conditions the results obtained from the Clinalyzer, although higher than when Vickersrecommended reagents were used, were still lower than those obtained with the AKES.

Clinalyzer $=0.89 \times($ AKES $)+2.7$

An experiment was carried out to investigate the effect of the different volume fractions used on the two instruments. Manual assays on a recording spectrophotometer were used because the AKES could not deliver a small enough volume of serum to reproduce the volume fraction in the Clinalyzer. Slightly higher results were obtained with the smaller volume fraction of serum. The use of a smaller volume fraction of serum could not therefore account for the lower results which the Clinalyzer produces in comparison with the AKES.

The effect of the addition of magnesium ions to the reaction mixture was investigated since the Boehringer reagents contain magnesium ions but the method recommended for the Clinalyzer does not. The addition of magnesium ions caused only a slight increase in the results.

$($ Buffer $+\mathrm{Mg})=1.016 \times($ Buffer without magnesium) $+5.0$

Urea - There is a very good correlation between the two methods. In comparison with the SMA $6 / 60$, the Clinalyzer overestimates urea at levels below $3 \mathrm{mmol} / 1$ and underestimates urea at levels above $3 \mathrm{mmol} / \mathrm{l}$. The same standard was used in both methods and, according to the Wellcome Quality Control Programme, our SMA $6 / 60$ produces results which show no significant bias relative to the "all method mean" or to our "own method mean". In the linearity check, recovery of added urea was $86 \%$ which is in agreement with the regression equation (slope $=0.86$ ) in the comparison with the selected method.

Protein - Correlation between the two methods is good and there is an almost $1: 1$ relationship with a small negative intercept. The same standard was used for both methods.

Bilirubin - When the whole range of values is taken into account, correlation between the two methods is excellent with the Clinalyzer 5\% lower than the SMA $12 / 60$. At levels within the "normal range" correlation is not quite so good and the Clinalyzer values are, on an average, $23 \%$ lower than the SMA $12 / 60$. This does not seem to be due to any difference in the blank value on the two instruments as the intercept on the graph is very small. The same standard was used in both methods. The SMA $12 / 60$ is only controlled at bilirubin levels above the "normal range" so the discrepancy may equally well be due to inaccuracy in either instrument.

\section{Interfering Factors}

Amounts of Intralipid (Kabivitrum Ltd., London), $(20-100 \mu \mathrm{l})$ were added to $1 \mathrm{ml}$ portions of a control serum (Versatol HI). This produced sera which could be subjectively assessed as ranging from moderately to severely lipaemic. The results of analysing these sera for protein and bilirubin are given in table 12 . The effect of lipaemia in other channels was small. Protein and bilirubin results could be clinically misleading if measured on lipaemic serum.

We assayed two control sera, one with elevated levels of all constituents (Autoset $\mathrm{H}$ ) and one with low levels of aspartate transaminase, alkaline phosphatase, urea and protein and a very high bilirubin level (Versatol Paediatric). A mixture of equal parts of the two sera was also assayed and the results for the mixture compared with the mean of the assay values for the sera. There was a close agreement (less than $2 \%$ difference) indicating that high levels of bilirubin do not cause interference in any other channel.

Tab. 12. Effect of Lipaemia on Protein and Bilirubin Assays.

\begin{tabular}{cll}
\hline $\begin{array}{l}\text { Intralipid added to } \\
1 \mathrm{ml} \text { serum }[\mu \mathrm{l}]\end{array}$ & $\begin{array}{l}\text { Protein }[\mathrm{g} / \mathrm{l}] \\
\text { Measured Level }\end{array}$ & $\begin{array}{l}\text { Bilirubin }[\mu \mathrm{mol} / \mathrm{l}] \\
\text { Measured Level }\end{array}$ \\
\hline 0 & 106 & 150 \\
20 & 152 & 144 \\
40 & 190 & 148 \\
60 & 222 & 163 \\
80 & 256 & 189 \\
100 & 300 & 227 \\
\hline
\end{tabular}

\section{Discussion}

The Clinalyzer is easy and pleasant to operate. It does not occupy much laboratory space. We were impressed by the ingenious yet simple design and the high standard of materials and robustness of construction employed. The instrument demonstrated virtually complete electrical and mechanical reliability during the evaluation.

After reagents have been made up at the start of the day and a calibration run carried out, operator attention is limited to changing sample trays. The shutdown procedure is rather long, however, taking 50 minutes.

Other favourable points from the evaluation are, the large range of concentration over which instrument response is linear, the good precision and a very low incidence of aberrant results.

It was felt that meaningful costings could not be made without experience of using the instrument to provide a routine service. However, the Clinalyzer is likely to prove a relatively cheap instrument to run for a number of reasons. The high standard of engineering employed in its manufacture should ensure a prolonged useful 
life. The excellent reliability should mean low maintenance and repair costs. The simplicity of operation means low staff costs. The facility for calibrating each channel with its own standard should do away with any need for costly "standard sera". Reagents and disposables required to run the instrument for a year, at 300 samples per day, will cost approximately $£ 4000$ using the sources of materials recommended by Vickers Medical. This evaluation shows that to obtain acceptable accuracy for enzyme assays materials of higher quality (and considerably greater cost) are necessary.

Turning to the disadvantages of the instrument, we feel it is inflexible. To alter the function of a channel may require modifications to the sampling valve, to a photometer and to the data processor. The configuration of the instrument must be decided at the time of purchase.

Although the instrument derives its exceptional dynamic range, in part, from the use of an unusually small serum sample, there could be objections to this approach.

Standardized methods for the determination of enzymes by reaction rate monitoring have so far all recommended volume fractions of serum larger than those used on the Clinalyzer $(3,4,5,6)$, and laboratories may wish to comply with these recommendations.

\section{References}

1. Broughton, P. M. G., Buttolph, M. A., Gowenlock, A. H., Neill, D. W. \& Skentelbery, R. G. (1969), J. Clin. Pathol. 22, 278-284.

2. National Committee for Clinical Laboratory Standards. Protocol for establishing the precision and accuracy of automated analytical systems. NCCLS publication (1975).

3. Deutsche Gesellschaft für Klinische Chemie: (1970), this J., $8,658-660$.
Because of the length of time required for run-up, calibration and run-down, the Clinalyzer is not suitable for emergency estimations out of laboratory hours.

The contamination of the serum sample with wash water and the consequent short-fall in sample size is an undesirable feature of the design. The volume of serum delivered by the sampling valve thus needs to be accurately measured on each instrument (as was done for this evaluation) since inaccuracy in kinetic enzyme assays would result were it to be assumed that the nominal sample volume is correct.

\section{Acknowledgements}

We should like to thank Vickers Medical for making the Jeol Clinalyzer available to us and for the invaluable help which their staff gave to us.

Our particular thanks to Mr. Isao Diago of Jeol Ltd., who gave us an excellent induction course on the instrument and spent some time with us in Glasgow, while we became familiar with the Clinalyzer. He also helped us with those parts of the evaluation where dismantling work on the instrument was needed.

We also thank staff of the Common Services Agency for the Scottish Health Service for carrying out the electrical safety check.
4. Deutsche Gesellschaft für Klinische Chemie: (1972), this J. $10,182-192$.

5. The Committee on Enzymes of the Scandinavian Society for Clinical Chemistry and Clinical Physiology. (1974), Scand. J. Clin. Lab. Invest. 33, 291.

6. Bergmeyer, H. U., Bowers, G. N. Jr., Horder, M. \& Moss, D. W. (1976), Clin. Chim. Acta 70, F19-F42; (1977), this J. 15, 39-51; (1977), Clin. Chem. 23, 887-899.
Dr. I. R. Hainsworth Principal Biochemist Gartnavel General Hospital 1053 Great Western Road Glasgow G 120 YN 
.

. 